\title{
Equipment for the Continuous Measurement and Identification of Gamma Radioactivity on Aerosols
}

\author{
Alfredo de Blas Member,IEEE, Juan Toral, Carlos Tapia, Albert Riego, Roger García, Javier Dies, Enric Batalla, \\ Pedro Diaz
}

\begin{abstract}
This paper describes an equipment for continuous measurement and identification of gamma radioactivity in aerosols developed by the Nuclear Engineering Research Group (NERG) at the Technical University of Catalonia (UPC) and Raditel Serveis i Subministraments Tecnològics, Ltd. A spectrometric analysis code has been specially designed for it. Spectrum analysis identifies and determines activity concentration of aerosol emitters captured by a fiberglass paper filter. This new equipment is currently operating in three radioactivity monitoring stations of the Environmental Radiological Surveillance Network of the Generalitat of Catalunya (local Catalan government): two near Ascó and Vandellòs Nuclear Power Plants in the province of Tarragona and one in the city of Barcelona. Two more monitors are expected to be deployed at Roses (province of Girona) and Puigcerdà (province of Barcelona). Measurements and evolution analysis results of emitters identified at these stations were also provided.
\end{abstract}

Index Terms-Gamma Spectrometry, radioactive aerosols, environment radiation monitors, gamma specific activity

\section{INTRODUCTION}

$\mathbf{P}$ rotection against environmental ionizing (mainly gamma) radiation requires the determination of the ambient dose equivalent $H^{*}(10)$ [1]. Nevertheless, this magnitude does not give information about the nature of radiation, i.e., the isotope emitting gamma radiation. To complement $\mathrm{H}^{*}(10)$, an equipment for continuous measurement of gamma radioactivity in aerosols with paper filter has been designed. An option to complement the $\mathrm{H}^{*}(10)$ measurement is the Berthold BAI985061, which measures beta particulates, radon and ${ }^{131}$ I activity. The BAI9850-61 uses a Single-Channel Analyzer and only detects ${ }^{131}$ I. Furthermore, to retain iodine, the BAI9850-61 employs a TEDA Impregnated Carbon Filter. This kind of filter difficult the continuous measurement. Another option are direct monitors of gamma radiation with spectrometric analysis, e.g. SARA monitor form TechniData among others. This kind of monitors are able to determine the gamma activity from aerosols. The equipment presented in this paper identifies continuously gamma emitting aerosols (natural and artificial emitters from nuclear power plant discharges or industrial applications, e.g. radio-iodines, ${ }^{137} \mathrm{Cs},{ }^{60} \mathrm{Co}$ or ${ }^{192} \mathrm{Ir}$ among others

Manuscript recieved May 26, 2015.

A. de Blas, C. Tapia, A. Riego, R. Garcia, J. Dies and P. Diaz are with the the Nuclear Engineering Research Group, Departament of Physics and Nuclear Engineering, Technical University of Catalonia, Barcelona, Spain. (Email:alfredo.de.blas@upc.edu)

J. Toral is with Raditel Serveis. Tarragona. Spain. (Email:raditelserveis@gmail.com)

E.Batalla is with the Radiological Activities Corrdination Service (SCAR) of the Generalitat de Catalunya. Barcelona. Spain. (Email:ebatalla@gencat.cat)
) and determines their activity concentration. Our equipment has been used by the Environmental Radiological Surveillance Network of the Generalitat de Catalunya since 2010. ${ }^{1}$ Three monitors are currently fully operative: two in the surveillance station of the Ascó and Vandellòs Nuclear Power Plants (both in the province of Tarragona, Spain), and one in the Engineering School of Barcelona, Spain. Two new monitors will shortly be deployed in Roses (province of Girona) and in Puigcerdà (province of Barcelona). These monitors have been designed and developed by the NERG (Nuclear Engineering Research Group) at the Technical University of Catalonia-Barcelona Tech and Raditel Serveis i Subministraments Tecnològics, Ltd.

\section{DESCRIPTION}

The equipment measures activity concentration in air of natural and artificial gamma emitters in aerosols captured by a fixed paper filter, and generates alarms depending on the measurements and emitters identified. Figure 1 is a photograph of the equipment and figure 2 is a block diagram. It is mainly made up of an air suction module, a filter, an air duct to the filter, a detection module and a control module. The suction module draws air from the outside and introduces it into the detection zone. Previously, the air passes through an air injection head and onto the filter, where a fraction of the heavier particles and aerosols is adhered. The efficiency of the filter is near $99 \%$ for all the particles. A special case is ${ }^{{ }^{131}} \mathrm{I}$ where only a fraction are particles the rest are gaseous species. The fraction particles on iodine depends on the atmospheric conditions during the transport of iodine. After a study of several researchers estimations from information collected during the Chernobyl and Fukushima accidents [2] and other measurements [3] we had adopted the Rascal criterion of $33 \%$ [4] for the fraction of particles in radio-iodine. The gamma radiations emitted by radionuclides that adhere to the filter are detected by the detection module, and the electric signal is processed to generate an energy spectrum. This spectrum is analyzed by a spectrometric analysis code, called pGamma, and a report of the activity concentration in air of each identified radionuclide is created. The detection time can be divided into partial periods where a partial spectrum is generated and analyzed, and a partial report is obtained.

Once the detection time ends, an electric positioning actuator lifts the air injection head to allow the paper filter roll to rotate such that a clean filter is ready for use for the next

\footnotetext{
${ }^{1}$ This network is integrated in the Spanish Nuclear Security Council network.
} 
measurements. Then, the positioning actuator returns the air injection head to its initial position.

The control module is composed of a network of sensors which monitor the status of the equipment. Their output signal is sampled by a data acquisition card and analyzed by control software. This software creates a report about the status of the equipment, allowing the user to perform control operations. All remote computer communications are made by the teleprocessing module and software.

A data acquisition card is connected in an expansion slot of an industrial computer. All the software is installed on this computer. For ease of maintenance and tuning operations the equipment is provided of a screen showing the spectrum and the main operation parameters.

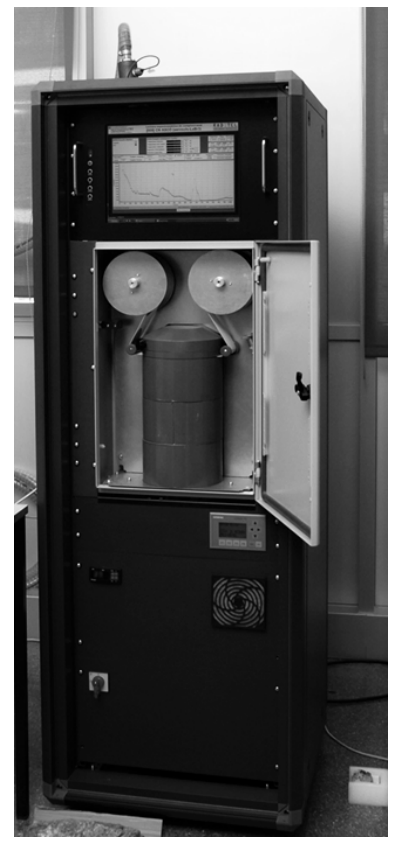

Figure 1. Equipment photograph

The detection zone is a cavity (figure 3 ) comprising a shielding, the air injection head, the paper filter, the detector casing with the $\mathrm{Sn}$ and $\mathrm{Cu}$ filters, the instrumentation and the detector. The shielding is a $5 \mathrm{~cm}$ thick lead cylinder with a top head and a bottom slab to absorb cosmic radiation and NORM radiation from soil. It has four ports: the air injection head, the air outlet and two windows for the paper filter roll. They were designed to minimize the solid angle between them and the window of the detector. The detector is lined with a PVC casing and $\mathrm{Sn}$ and $\mathrm{Cu}$ filters. This casing directs the air once it has passed through the filter and facilitates the removal of the detector, and the $\mathrm{Sn}$ and $\mathrm{Cu}$ filters absorb X-rays.

Since this equipment is intended for environmental surveillance, the air flow is in the order of $10 \mathrm{~m}^{3} / \mathrm{s}$. That is why the filter is unlikely to break or become saturated. This allows the use of a fixed paper filter, with which activity concentration can be directly determined. This is not possible with moving filters [5]. Moreover, a paper filter allows continuous measurement with automatic movement of the filter when a new counting starts. The filter is a glassfiber GF 10 from

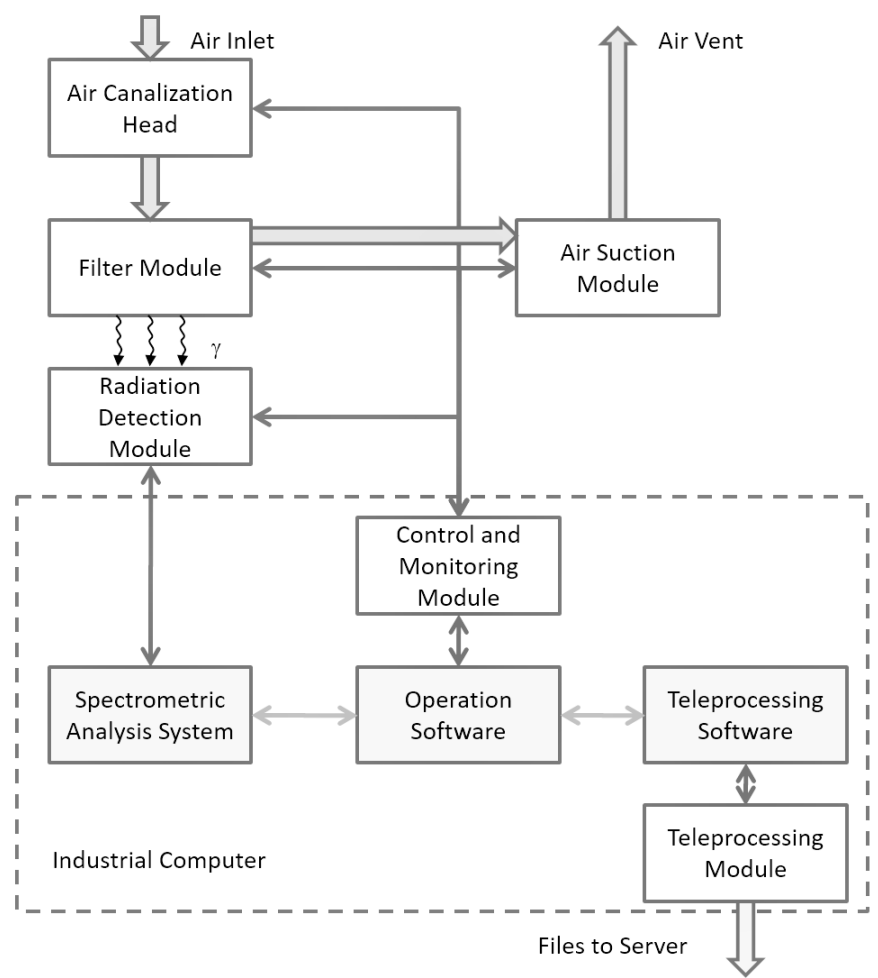

Figure 2. Architecture of the monitor

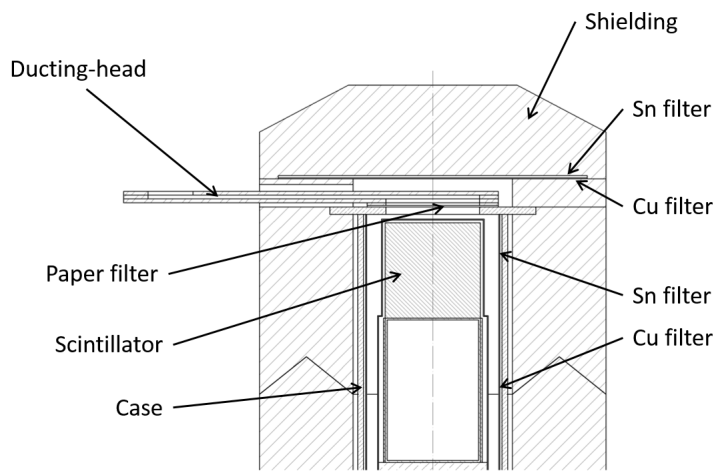

Figure 3. Plot of the detection zone

Hahnemühle (100\% borosilicate) with organic links used in roll form. This kind of filters has an efficiency of 99\% for the particles of interest - taking as a reference Whatman-41 filter (ours has better performance) - [6], [7].

A 2" x 2" $\mathrm{LaBr}_{3}(\mathrm{Ce})$ scintillator detector is used to detect gamma radiation retained on the filter. $\mathrm{LaBr}_{3}(\mathrm{Ce})$ scintillators have a better resolution, are less sensitive to temperature but their intrinsic spectrum is more intense than the classic $\mathrm{NaI}(\mathrm{Tl})$ spectrum. This is a drawback, but it can be useful. The intrinsic peak due to $1436 \mathrm{keV}$ gammas of ${ }^{138} \mathrm{La}$ (which, together with the sum peak of $32 \mathrm{keV} \mathrm{X}$-rays and $1436 \mathrm{keV}$ gammas, forms a multiple peak or multiplet) is used as a reference peak for spectrum stabilisation. To test stabilisation, the equipment was subject to a temperature test consisting in sudden variations in intake air temperature, combined with suction phases of cold outside air and of previously heated air. Figure 4 shows one 
of these tests. After the variations of $18{ }^{\circ} \mathrm{C}$, the centroid of peaks remains in the same channel. Under normal operating conditions, no abrupt changes in temperature, such as those in the tests, ever occur. The drawback of using the intrinsic ${ }^{138} \mathrm{La}$ full energy peak as a reference is the influence of another gamma emitter with an energy greater than $1436 \mathrm{keV}$. To demonstrate this, two scenarios were analyzed: the effect of the sum peak of ${ }^{60} \mathrm{Co}$ (an artificial gamma emitter) and the effect of the full energy peaks of the ${ }^{238} \mathrm{U}^{222} \mathrm{Rn}$ series with an energy greater than $1450 \mathrm{keV}$, mainly ${ }^{214} \mathrm{Bi}$. Under normal operating conditions, ${ }^{214} \mathrm{Bi}$ photons with energies greater than $1450 \mathrm{keV}$ do not generate a Compton continuum intense enough to overlap the full energy peak of ${ }^{138} \mathrm{La}$. The sum peak of ${ }^{60} \mathrm{Co}(1137 \mathrm{keV}+1332 \mathrm{keV}=2496 \mathrm{keV})$ generates a Compton continuum capable of overlapping the reference peak. In this case, before reaching the activity level of ${ }^{60} \mathrm{Co}$ required to overlap the ${ }^{138} \mathrm{La}$ peak, the system will switch to investigation mode and alarm mode.

A spectrometric analysis code, called pGamma, specially designed by the NERG research team for the equipment described here analyzes spectra to identify emitters associated with existing peaks and determine their activity concentration. This code, includes a library with NORM and artificial gamma emitters of interest. In addition, it is more suitable than other commercial codes because it allows automatic operation of the equipment. pGamma has two operation modes, i.e. normal operation mode and investigation mode. In normal operation, pGamma only searches for NORM peaks, but when one of the following conditions is fulfilled it switches to investigation mode: 1) an identified emitter has an activity greater than an empirical threshold; 2) a significant peak has not been identified; and 3) the derivative of whole spectrum counts (without the lower channels) is greater than an empirical threshold. In investigation mode, pGamma searches for artificial emitters. Two levels of alarm are generated depending on the activity concentration of at least one of the identified emitters.

The identification of ${ }^{131} \mathrm{I}$ in nuclear fallout is worth mentioning. This emitter can be detected with the equipment, but its minimum detectable activity is higher than for other emitters and activity concentration can be estimated only because of the filter used, which only retains iodine particles while letting other iodine species pass. The iodine species on a specific location depends on the atmospheric conditions during iodine transport. Thus, it is impossible to accurately determine the activity of ${ }^{131}$ I. However, this is not a problem because the equipment is intended for surveillance and its final purpose is to generate alarms

The purpose of the equipment is not to identify all peaks in the energy spectrum, but only those whose peak net area is greater than a significance threshold. When this condition is met, the code tries to identify them. This increases the minimum detectable activity, but avoids excessive meaningless information. The minimum detectable activity in normal operating conditions, for $24 \mathrm{~h}$ spectra, is $0.02402 \mathrm{~Bq} / \mathrm{m}^{3}$ for ${ }^{60} \mathrm{Co}, 0.01662 \mathrm{~Bq} / \mathrm{m}^{3}$ for ${ }^{137} \mathrm{Cs}$ and $0.4 \mathrm{~Bq} / \mathrm{m}^{3}$ for ${ }^{131} \mathrm{I}$, with the last one being a special case due the above reasons.
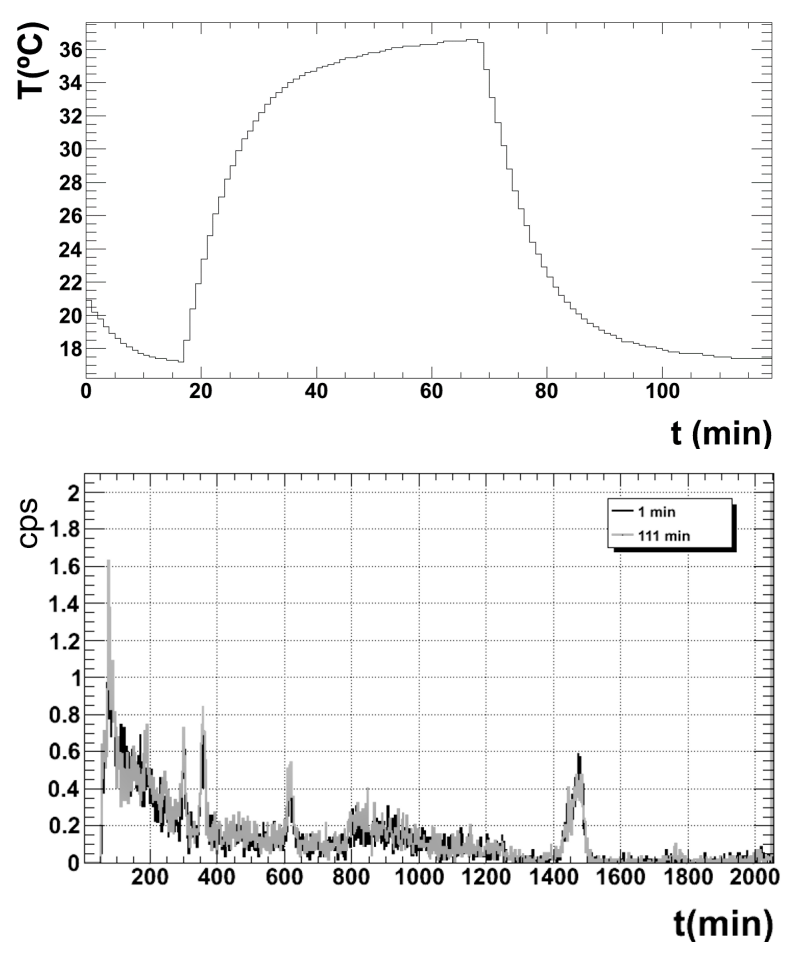

Figure 4. Temperature test to verify the spectrum stabilization

\section{RESULTS}

The following experimental results were obtained by the equipment in the three stations of the Environmental Radiological Surveillance Network of the Generalitat de Catalunya. The Ascó station and two monitors (of an older version than the one presented here) are shown in figure 5. In normal operating conditions, only the contribution of natural emitters ${ }^{212} \mathrm{~Pb},{ }^{214} \mathrm{~Pb}$ and ${ }^{214} \mathrm{Bi}$ appears in the report. Figure 6 shows the evolution of their activity concentration at the Ascó and Vandellòs stations during January 2015, also the corresponding Minimum Detectable Activity (MDA) is shown in Figure 7. The concentration of natural emitters is greater in Ascó than in Vandellòs due the geographical situation of both nuclear power plants. Since Ascó is close to the Ebro river and Vandellòs is near the sea, the source term of naturals in Ascó is greater. Figure 8 shows the ${ }^{214} \mathrm{Bi} / 214 \mathrm{~Pb}$ ratio, which is within the typical range of values, as can be seen in [3]. Figure 9 shows the activity concentration of ${ }^{214} \mathrm{~Pb}$ on the monitors of the Ascó and Barcelona stations on 1-2 January 2015. The relation between temperature and activity in air is exactly as expected [3].

Figure 11 shows the report generated by the spectrometric analysis code pGamma (installed on the monitor) of a typical of a typical $24 \mathrm{~h}$ spectrum obtained at Ascó station on 10 January 2015 (figure 10). This report is employed by the manager of the network to generate the official report given to the Spanish Nuclear Security council. The report has four blocks: 1) overall parameters of the spectrum; 2) specific activity of identified isotopes (first column for activity, second for error, third for detectable activity and fourth the peaks associated with the isotope); 3) identified peaks on the 


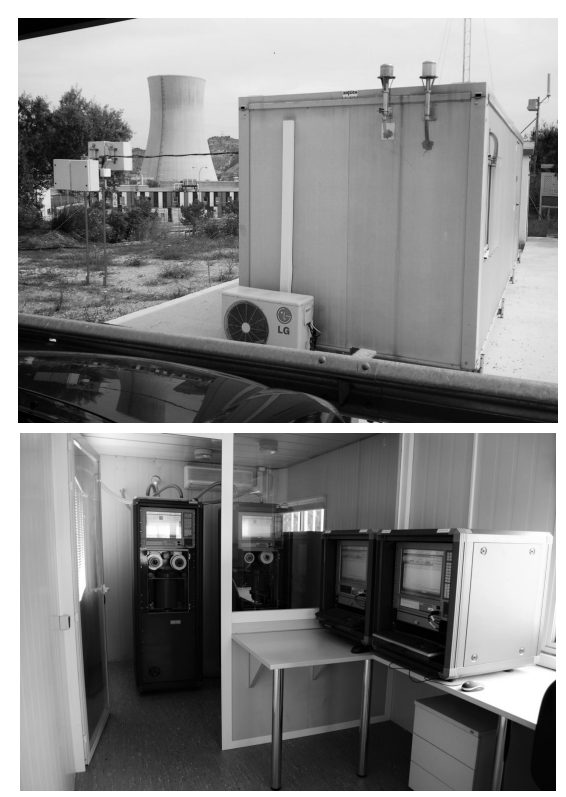

Figure 5. Station of the Nuclear Power Plant of Ascò (Tarragona, Spain)
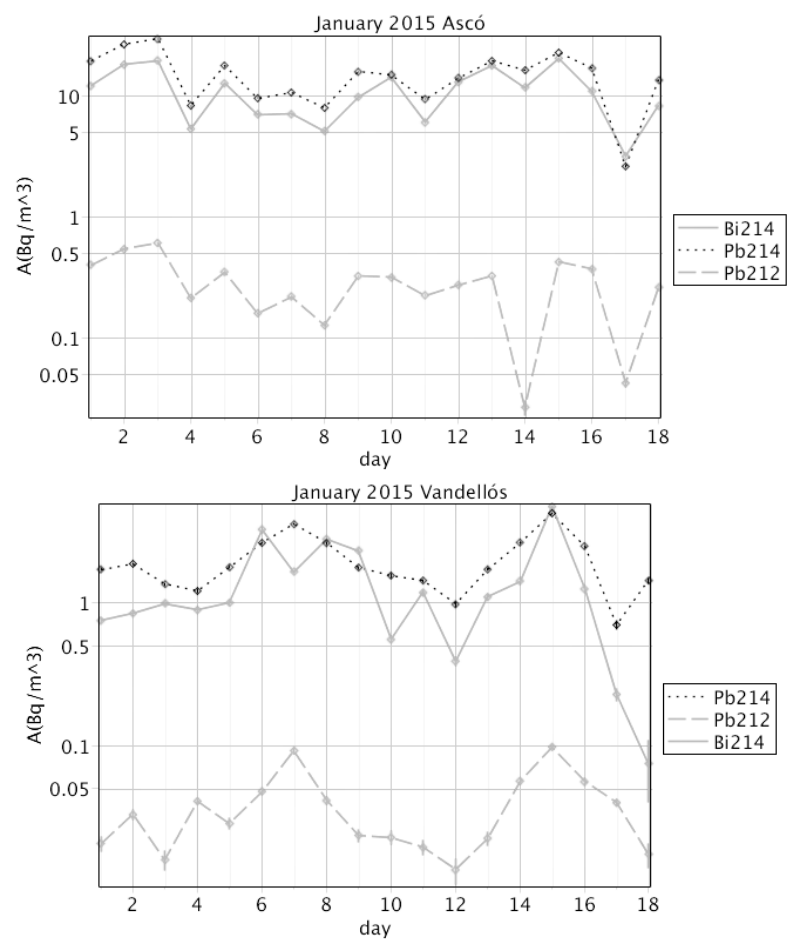

Figure 6. Concentration of activity on January 2015, in the stations of Ascò and Vandellós

spectrum with the information of each peak (centroid channel, energy, channels of the limits of the peak , FWHM, net area) ; and 4) unidentified peaks.

\section{CONCLUSIONS}

The Equipment for Continuous Measurement of Gamma Radioactivity in Aerosols with Paper Filter presented here determines the activity concentration of gamma emitters in
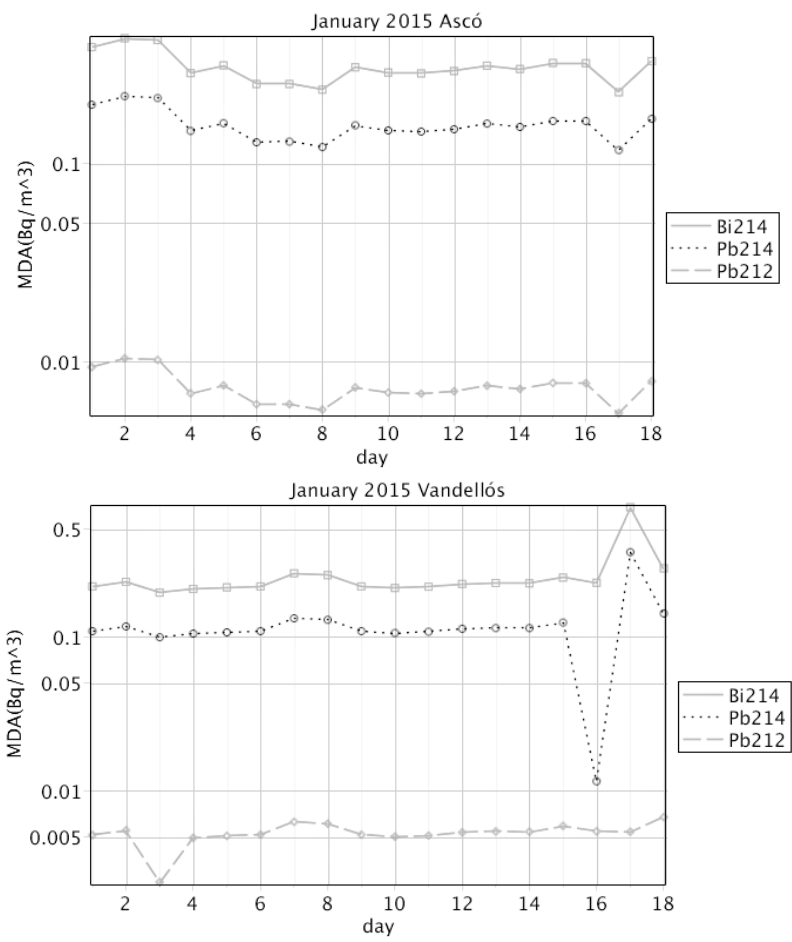

Figure 7. Minumum Detectable Activity (MDA) on January 2015, in the stations of Ascò and Vandellós

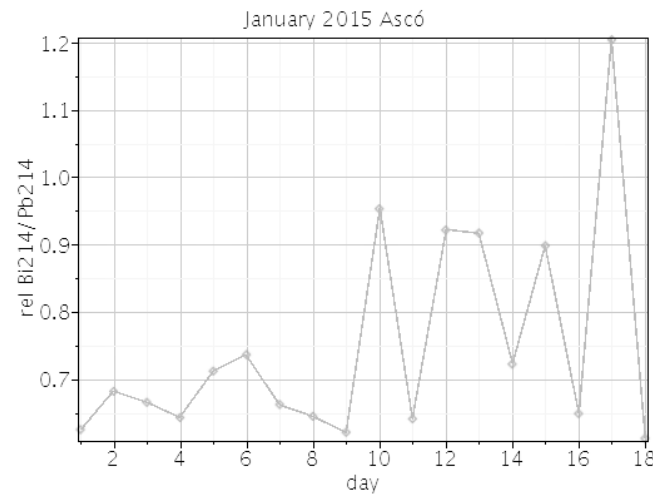

Figure $8 .{ }^{214} \mathrm{Bi} / 214 \mathrm{~Pb}$ rate in the station of Ascó

aerosols and detects the presence of ${ }^{131} \mathrm{I}$. It complements the information given by $H^{*}(10)$ monitors, allowing the investigation of the radiation source. The equipment operates remotely on networks in combination with other monitors. It generates partial and global spectra, monitors variations in the counts in partial spectra, and finally generates a report of each counting period. Alarms are generated when an emitter's activity concentration exceeds a set limit or an artificial emitter is identified.

\section{REFERENCES}

[1] Quatities and Units in Radiation Protection Dosimetry. ICRU Report 51., ICRU Std., 1993.

[2] S. MacMullin, G. Giovanetti, M. Green, R. Henning, R. Holmes, K. Vorren, and J. Wilkerson, "Measurement of airborne fission products in chapel hill, nc, usa from the fukushima dai.ichi reactor accident," Journal of Environmental Radioactivity, vol. 112, pp. 165-170, 2012. 

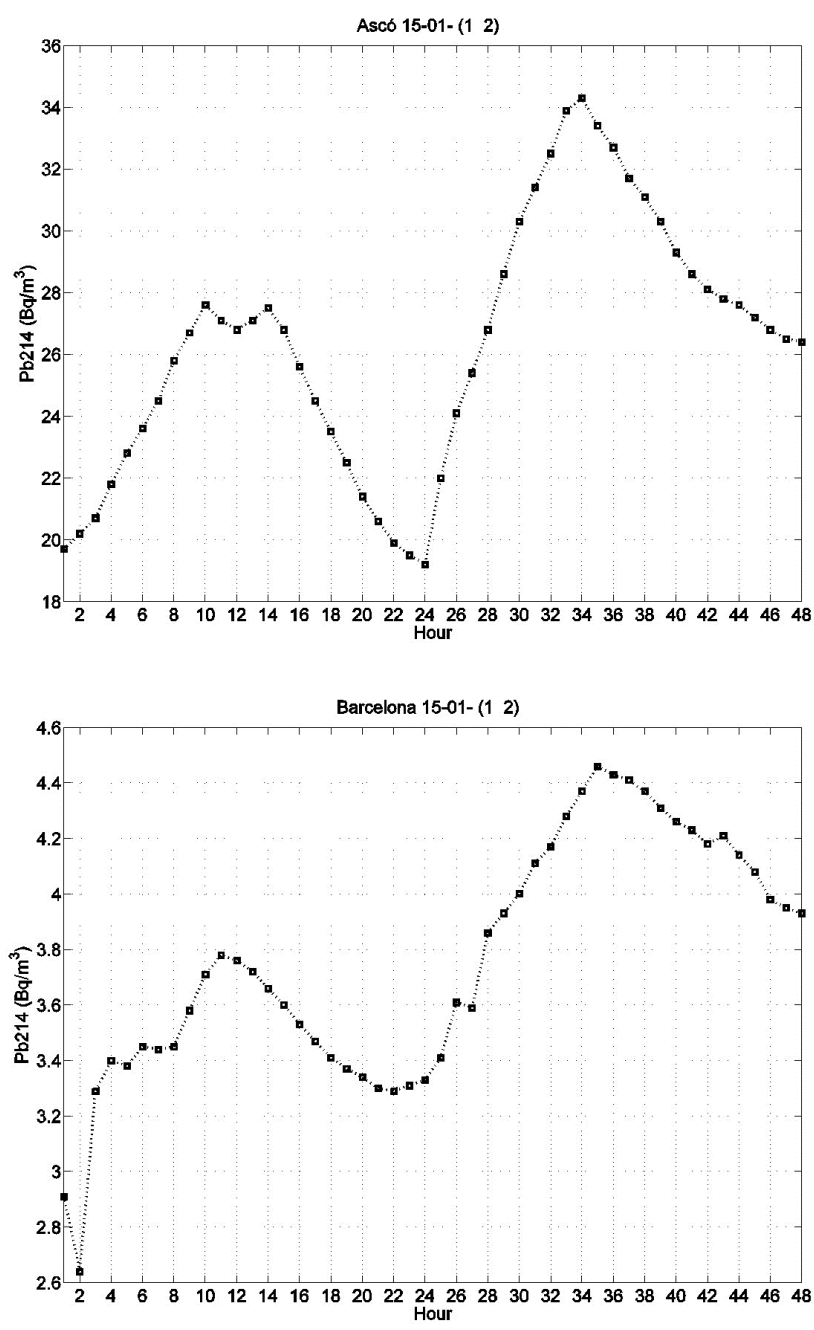

Figure 9. Evolution of the specific activity of ${ }^{214} \mathrm{~Pb}$ the days 2015/01/01 and 2015/01/02 on the stations of Ascó and Barcelona

[3] A. C. Chamberlain, Radioactive Aerosols, 1st ed. Cambridge University Press, 1991.

[4] J. Ramsdell Jr, "Rascal 4.3. dispersion and deposition models," in 18th Annual George Mason University Conference on Atmospheric Transport and Dispersion Modelling, 2014.

[5] W. Evans, "Incorrect interpretation of moving-filter continuous particulate air monitor responses," Health Physics, vol. 104 no.4, pp. 437-443, 2013.

[6] W. John and G. Reischl, "Measurements of the filtration efficiencies of selected filter types," Atmospheric Environment, vol. 12, pp. 2015-2019, 1978.

[7] E. Kitto and D. Anderson, "The use of whatman-41 filters for particle collection," Atmospheric Environment, vol. 22. No.11, pp. 2629-2630, 1988.

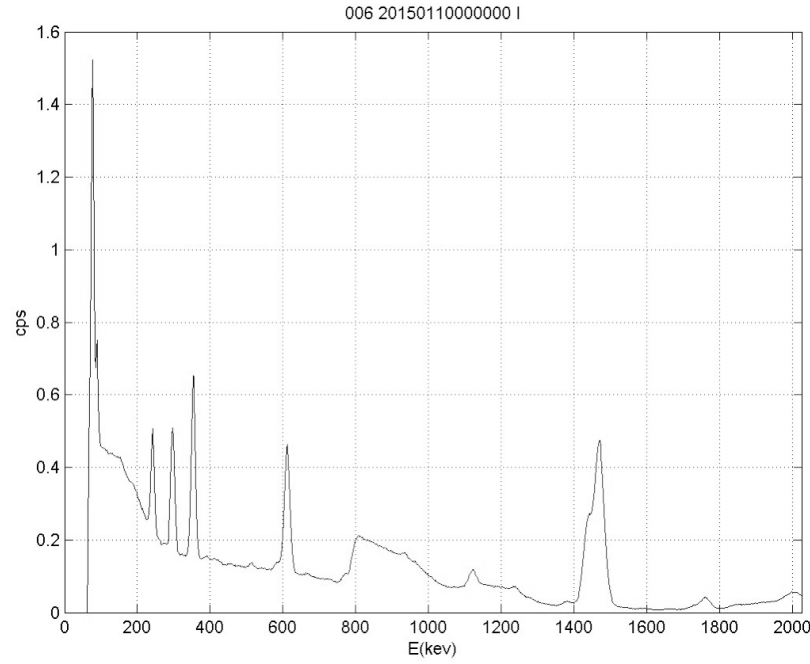

Figure 10. Spectrum from Ascó station 10 January 2015

[1]

\section{8}

10179770

[2]

pb212 Th232Rn220Series $3.15 \mathrm{e}-001 \quad 3.56 \mathrm{e}-003 \quad 6.98 \mathrm{e}-0031$ bi214 U238Rn222Series $1.42 \mathrm{e}+0018.05 \mathrm{e}-002 \quad 2.88 \mathrm{e}-00171011$ $\begin{array}{lllll}12 & 13 & 17 & 18\end{array}$

pb214 U238Rn222Series $1.49 \mathrm{e}+001 \quad 7.23 \mathrm{e}-002 \quad 1.47 \mathrm{e}-00123$ [3]

$\begin{array}{llllllllll}\text { pb212 } & 1 & 121.1 & 241.7 & 241.8 & 4.4 & 115 & 133 & 14.4 & 135857.7\end{array}$ Th232Rn220

bi214 $7307.0 \quad 611.0 \quad 609.6 \quad 9.6 \quad 286326 \quad 20.9 \quad 302812.7$ U238Rn222

bi214 $10 \quad 467.6 \quad 932.4 \quad 936.5 \quad 5.4 \quad 464 \quad 479 \quad 18.4 \quad 5440.6 \quad$ U238Rn222 bi214 $11 \quad 561.5 \quad 1121.2 \quad 1120.2 \quad 9.5 \quad 542 \quad 574 \quad 26.7 \quad 44514.1$ $\mathrm{U} 238 \mathrm{Rn} 222$

bi214 $12618.1 \quad 1235.2 \quad 1238.1 \quad 6.3 \quad 612667 \quad 23.1 \quad 8134.9$ U238Rn222

bi214 $13690.1 \quad 1380.9 \quad 1375.5 \quad 7.1676 \quad 695 \quad 19.7 \quad 4868.6$ U238Rn222

bi214 $17876.3 \quad 1759.3 \quad 1753.0 \quad 17.6 \quad 846894 \quad 33.7 \quad 51719.2$ U238Rn222

bi214 $18921.8 \quad 1852.1 \quad 1841.19 .9902927 \quad 30.14166 .6$ U238Rn222

$\begin{array}{llllllllll}\mathrm{pb} 214 & 2 & 148.9 & 296.7 & 296.9 & 4.8 & 142 & 158 & 17.3 & 178632.9\end{array}$

U238Rn222

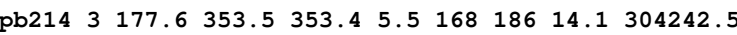
$\mathrm{U} 238 \mathrm{Rn} 222$

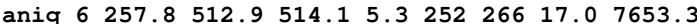

Annihilation peak

$\begin{array}{llllllllll}1 \text { la138 } & 9 & 405.2 & 807.1 & 818.3 & 19.8 & 391 & 438 & 52.7 & 172130.3\end{array}$

Intrinsic

$\begin{array}{lllllllllll}\text { la138 } & 14 & 733.3 & 1468.4 & 1468.6 & 7.8 & 723 & 780 & 21.9 & 229245.5\end{array}$

Intrinsic

[4]

[5]

Figure 11. Report with the analysis of pGamma 